\title{
Federal autism committee names new members
}

\author{
BY LAURA DATTARO
}

7 JULY 2021

The U.S. government today announced the latest iteration of the Interagency Autism Coordinating Committee (IACC), the body of scientists and advocates that helps set priorities for federally funded autism research and services.

The committee plans to hold a public meeting virtually on July 21 and 22 , the first IACC meeting since July 2019. Based on input from incoming IACC members, the meeting will include sessions on how the coronavirus pandemic and racial inequalities have affected autism research, IACC executive secretary Susan Daniels wrote in an email to Spectrum.

The new IACC is composed of 22 public members -2 of whom served on the previous committee - and 23 representatives from a variety of federal agencies. The public members include researchers, clinicians, autistic self-advocates, parents of people with autism, and representatives from autism and disability organizations. (One member, Paul Wang, is employed by the Simons Foundation, Spectrum's parent organization.)

Seven of the public members - nearly one-third - are autistic, representing a "dramatic change" from past IACC rosters, says Sam Crane, legal director of the Autistic Self Advocacy Network (ASAN) and a returning IACC member. One new member communicates by typing rather than speaking, and another has intellectual disability, she says.

"That's really good that we're increasing the diversity of voices on the IACC," Crane says. "It could be a really good opportunity to start talking about doing better research on communication supports."

In addition to Crane, Julie Lounds Taylor, associate professor of pediatrics at Vanderbilt University Medical Center in Nashville, Tennessee, is also remaining on board. 


\section{Funding focus:}

The 2019 Autism CARES Act designates $\$ 369.7$ million for annual federal autism spending through 2024, an increase over the $\$ 260$ million outlined in the 2014 version of the law. It also requires that the IACC include at least three autistic people, three parents or guardians of an autistic person, and three representatives from research, advocacy or service organizations - an increase from two members of each group.

Four federal agencies have joined the committee for the first time: the Department of Housing and Urban Development, the Department of Labor, the Department of Veteran Affairs, and the Department of Justice, which will offer expertise on interactions between autistic people and police officers, according to a press release.

"We are excited to welcome the largest and most diverse IACC to date, with a wider representation of perspectives from across the autism community than ever before," Daniels wrote in an email to Spectrum.

Daniels is also serving as the acting National Autism Coordinator after the previous coordinator, Ann Wagner, retired on June 30.

The addition of the new agencies may help the IACC and, by extension, the government address urgent needs for autistic people, such as housing, says Helen Tager-Flusberg, professor of psychological and brain sciences at Boston University and a newly appointed public member.

"It's really quite a privilege to be able to serve," Tager-Flusberg says. "I'm hoping that we can really get the ear of the people who need to hear what's really needed for the community, both in terms of pushing the science forward but also the very real and neglected needs of the community."

While the increased representation of autistic people on the IACC is important, Crane says, the group should also focus on shifting federal funding toward areas many autistic people see as priorities, such as autism in adults and long-term services and supports.

"Representation isn't the end of the story," she says. "Hopefully when you change who's on the committee, you can also change the tone of the conversation."

Cite this article: https://doi.org/10.53053/YAWT7600 